DOI: 10.12731/2070-7568-2020-4-296-312 УДК 332.1

\title{
ТЕОРЕТИЧЕСКИЕ ПОДХОДЫ К КЛАССИФИКАЦИИ ФАКТОРОВ РАЗВИТИЯ РЕГИОНА И СПОСОБАМ ИХ АНАЛИЗА
}

\section{Москвитина М.A.}

В современных условиях управление развитием регионов базируется преимущественно на реализащии государственных федеральных и региональных программ и поддержке федеральным иеентром наиболее отстальх регионов. В то же время исследованию факторов развития регионов в практике государственного управления уделяется не достаточно внимания. В теории существуют многочисленные разрозненные подходы к классификации факторов развития региона, факторы рассматриваются без взаимосвязи с методами их исследования, отсутствуют методических схемы их анализа. В статье приводится анализ понятия «фактор», исследуются различные, как традиционные, так и авторские классификации факторов развития региона, систематизируются методы анализа факторов развития региона.

Цель - систематизация подходов к классификации факторов развития региона и формирование схемы их исследования.

Метод и методология: общенаучные методы теоретического исследования: анализ и синтез, систематизащия, классификация и обобщение.

Результаты: предлагается обобщающая схема факторов развития региона («поле» факторов развития региона) и схема их исследования.

Область применения: рассмотренные в работе теоретические аспекты классификации и подходов к оценке факторов развития региона могут являться элементом методической базы конкретных региональных исследований, а также могут быть полезны научным работникам, интересующимся данной проблемой. 
Ключевые слова: фактор; развитие региона; классификация факторов развития региона; анализ развития региона; оченка факторов развития региона.

\section{THEORETICAL APPROACHES TO THE CLASSIFICATION OF REGIONAL DEVELOPMENT FACTORS AND METHODS OF THEIR ANALYSIS}

\section{Moskvitina M.A.}

In modern conditions, the management of regional development is based primarily on the implementation of state federal and regional programs and the support of the most backward regions by the federal center. At the same time, not enough attention is paid to the study of the factors of regional development in the practice of public administration. In theory, there are multiple approaches to the classification of factors in the development of a region. Factors are considered without interrelation with the methods of their study. There are no methodological study design for their analysis. The article analyzes the concept of "factor", investigates various, both traditional and author's classifications of factors in the development of the region, systematizes the methods of analysis of factors in the development of the region.

Purpose. The systematization of approaches to the classification of regional development factors and to offer a study design for their analysis.

Method and methodology of the work: general scientific methods of theoretical research: analysis and synthesis, systematization, classification and generalization.

Results: a generalizing scheme of regional development factors ("field" of regional development factors) and a study design for their analysis.

Scope of the results: the theoretical aspects of the classification and approaches to assessing the factors of regional development considered in the work can be an element of the methodological base of specific regional studies, and can also be useful to scientists interested in this problem. 
Keywords: factor; regional development; classification of regional development factors; analysis of regional development; analysis of regional development factors.

Как известно, состояние экономической системы Российской Федерации в целом и ее отдельных регионов подвержено перманентным изменениям. Такие изменения являются органичными и отражают сущностные признаки экономики региона как базовой части его социально-экономической системы. В то же время в современных условиях всеобщей нестабильности, проявляющейся в череде глобальных кризисов, ограничений, вызванных пандемией SARS-CoV-2, изучение направлений, факторов развития экономики регионов России становится наиболее важным. Уяснение факторов развития региона и их оценка дают возможность органам управления региона принимать наиболее эффективные в сложившихся обстоятельствах управленческие решения, ориентируясь не только собственно региональные возможности, но и общегосударственную политику.

В научной литературе сформировались устоявшиеся подходы к определению понятия «фактор». Так, например, словарь С.И. Ожегова определяет фактор, как момент, существенное обстоятельство в каком-нибудь процессе, явлении [1]. Особенностью данного подхода является, на наш взгляд, то, что в качестве фактора определяются не только существенные обстоятельства, но и время также рассматривается как фактор. Это особенно важно для управления социальноэкономическими системами любого уровня, т.к. своевременность управленческих решений является одним из признаков их качества.

Большая Советская энциклопедия трактует фактор (лат. factor «делающий, производящий»), как причину, движущую силу какого-либо процесса, определяющую его характер или отдельные его черты [2]. Такой подход указывает не только и не столько на изменения, под воздействием некоторых причин, но и на предопределенность характера и направленности таких изменений в зависимости от качества и характеристик самих причин (движущих сил). Такой аспект также важен для субъекта управления, т.к. позволяет, исходя 
из особенностей факторов, прогнозировать динамику и направленность изменений объекта управления и предусматривать соответствующие стимулирующие или ограничивающие (ограждающие) управленческие воздействия.

В представленных подходах понятие «фактор» отождествляется с понятием «причина». Также в научной литературе можно встретить и отождествление понятий «фактор» и «условие». В этом случае формируется нарушение логического принципа транзитивности: фактор $=$ причина; фактор $=$ условие; но причина $\neq$ условие.

Как известно, условия создают общую атмосферу функционирования социально-экономических систем, являются теми предпосылками, и объективными обстоятельствами, без которых развитие системы (переход от одного состояния к другому) невозможно. Поэтому понятие «условие» имеет, как правило, позитивную окраску. Причины же оказывают непосредственное воздействие на системы, предопределяя их развитие в разных направлениях (как прогресс, так и регресс). Следовательно, в некотором смысле, факторы включают в себя как условия, так и причины развития экономики региона.

Так, с учетом вышеизложенного, факторы развития региона это условия, причины, существенные обстоятельства (предпосылки), движущие силы процесса развития социально-экономической системы региона, определяющие его характер или отдельные его черты в конкретный момент времени. Необходимо отметить, что в современных условиях чертами конкретного момента времени становится и цифровизация государственного управления, стимулирование развития цифровых технологий, цифровизации экономики, реализация концепции смарт-сити.

Уже само определение понятия «фактор» свидетельствует о их множественности, многогранности, иерархичности, часто взаимоподчиненности, что делает процесс изучения факторов развития региона достаточно сложным и неоднозначным.

В современной научной литературе сложились многочисленные, как традиционные, так и авторские классификации факторов развития региона (см. таблица 1). 
Таблицуа 1.

Систематизация общепринятых классификаций факторов развития региона

\begin{tabular}{|c|c|}
\hline $\begin{array}{c}\text { Критерии } \\
\text { классификации }\end{array}$ & Факторы \\
\hline $\begin{array}{l}\text { 1. По отношению } \\
\text { ко внешней среде } \\
{[3,4]}\end{array}$ & $\begin{array}{l}\text { 1.1. Внешние (экзогенные): } \\
\text { А) факторы внешней среды косвенного воздействия: } \\
\text { - общеэкономические; } \\
\text { - общеполитические; } \\
\text { - научно-технические; } \\
\text { - природно-экологические; } \\
\text { - демографические } \\
\text { Б) факторы внешней среды прямого воздействия - взаи- } \\
\text { мосвязи с партнерами: } \\
\text { - внешними поставщиками товаров и услуг; } \\
\text { - внешними потребителями; } \\
\text { - регионами-конкурентами; } \\
\text { - финансовыми организациями; } \\
\text { - транспортными предприятиями } \\
\text { 1.2. Внутренние (эндогенные): } \\
\text { - производственно-ресурсный потенциал региона; } \\
\text { - структура регионального рынка; } \\
\text { - кадровый потенциал региона; } \\
\text { - региональный бюджет; } \\
\text { - стратегия развития региона. }\end{array}$ \\
\hline $\begin{array}{l}\text { 2. По сфере (с } \\
\text { разной степенью } \\
\text { детализации сфер) } \\
{[5,6]}\end{array}$ & $\begin{array}{l}\text { 2.1. Экономические: } \\
\text { - Экономико-географические; } \\
\text { - Экономические } \\
\text { - Расширение рынка (как внутреннего, так и внешнего) } \\
\text { - Структура экономики, степень ее диверсификации и др. } \\
\text { 2.2. Неэкономические: } \\
\text { - Природные } \\
\text { - Демографические } \\
\text { - Политико-административный фактор } \\
\text { - Геополитический } \\
\text { - Фактор НТП, инноваций } \\
\text { - Качество городской среды крупнейших городов региона } \\
\text { - Человеческий капитал } \\
\text { - Административные и экономические барьеры взаимодей- } \\
\text { ствия } \\
\text { - Имидж, престиж региона и пр. }\end{array}$ \\
\hline $\begin{array}{l}\text { 3. По типу ресур- } \\
\text { сов и условий [7] }\end{array}$ & $\begin{array}{l}\text { 3.1. Энергетический } \\
\text { 3.2. Водный } \\
\text { 3.3. Трудовой } \\
\text { 3.4. Земельный } \\
\text { 3.5. Сырьевой } \\
\text { 3.6. Транспортный (инфраструктурный) }\end{array}$ \\
\hline
\end{tabular}


Окончание табл. 1.

\begin{tabular}{|l|l|}
\hline $\begin{array}{l}\text { 4. По зависимости } \\
\text { от субъекта, при- } \\
\text { нимающего реше- } \\
\text { ния [8] }\end{array}$ & $\begin{array}{l}\text { 4.1. Объективные } \\
\text { 4.2. Субъективные }\end{array}$ \\
\hline $\begin{array}{l}5 . \text { По характеру } \\
{[9,10]}\end{array}$ & $\begin{array}{l}\text { 5.1. Экстенсивные } \\
\text { 5.2. Интенсивные }\end{array}$ \\
\hline $\begin{array}{l}\text { 6. По возможности } \\
\text { воздействия со } \\
\text { стороны субъекта } \\
\text { управления [11] }\end{array}$ & $\begin{array}{l}\text { 6.1 Контролируемые (в компетенции руководства региона) } \\
\text { региона) }\end{array}$ \\
\hline $\begin{array}{l}\text { 7. По уровнюлороз- воз- } \\
\text { действия [12] }\end{array}$ & $\begin{array}{l}\text { 7.1. Общенациональные } \\
\text { 7.2. Отраслевые }\end{array}$ \\
\hline
\end{tabular}

Существует также множество авторских подходов к выделению факторов развития регионов. Например, Нивейкина Н.В.[13] идентифицирует такие факторы развития региона, как территориальные, административные, экономические, институциональные, организационные, демографические.

Кузнецова О.В. [14] среди основных факторов описывает “субъективные" факторы (социально-экономическая политика государства в самом широком смысле), уровень развития и структура экономики, обеспеченность инфраструктурой, система расселения и демографические характеристики, природно-климатические условия и ресурсы. Причем подчеркивается, что факторы регионального развития играют разную роль, имеют иерархичный характер (от базового фактора природно-климатических условий и ресурсов до «высшего» «субъективного» фактора), представляются в виде некоторой пирамиды, напоминающей пирамиду А. Маслоу. Иерархичность представления факторов означает, что наряду с базовыми факторами присутствуют и факторы более высокого порядка, более сложные факторы. Они начинают играть свою роль тогда, когда базовые факторы достаточно благоприятны. Вместе с тем в ряде случаев неблагоприятность базовых факторов может быть некоторым образом преодолена, компенсирована более сложными факторами. Такой нетривиальный подход к выделению и обоснованию факторов развития региона представляется чрезвычайно интересным, т.к. об- 
условливает необходимость обеспечивать развитие регионов, как на уровне региональных, так и на уровне федеральных властей (часть факторов от региона мало или вовсе не зависит).

Кроме того, управленческие воздействия по развитию регионов не могут сводиться к политике стимулирования, но должны носить более сложный и системный характер, связанный с поиском наиболее адекватных для конкретного набора факторов, а значит и конкретного региона, форм, механизмов и инструментов его развития.

Минаев Ю.Н. [4] предлагает выделять «мягкие» и «жесткие» факторы. «Жесткие» факторы могут быть оценены количественно. К ним Ю.Н. Минаев относит:

- факторы, ориентированные на производственные ресурсы земля, рабочая сила, капитал;

- факторы, ориентированные на производство и сбыт продукции - близость партнеров по кооперации, инфраструктура, структура населения и потребления;

- факторы, установленные государством - налоги, система хозяйствования, субсидии и программы поддержки.

«Мягкие» факторы, соответственно, однозначной количественной оценки не имеют или она затруднительна. К ним Ю.Н. Минаев относит стабильность политической ситуации, стабильность общественного климата, квалификацию занятых по найму, региональную структуру экономики и отдельных предприятий, качество системы образования и профессиональной подготовки кадров; оснащение региона вузами, технологическими центрами, исследовательскими организациями.

Кроме работ различных авторов, в которых предпринимаются попытки классификации факторов социально-экономического развития регионов, множество отечественных и зарубежных исследований направлено на изучение отдельных факторов развития региона. Как правило, к ним относят регулирующие воздействия [15], глобальные и региональные тренды, инновационную [16] и предпринимательскую $[17,18]$ активность, ресурсный потенциал, 
в т.ч. социальной сферы, конкурентоспособность, освоенность территории [19] и производительность [20], строительство отдельных объектов или реализацию отдельных программ в регионе и другие условия и причины развития регионов.

Обобщая имеющиеся классификации факторов развития регионов (см. рисунок 1), можно сделать следующие заключения:

1) все представленное многообразие факторов описывает условия и причины развития региона только от части, т.к. всегда существуют и другие факторы, выходящие за рамки рассматриваемых;

2) многообразие факторов выдвигает задачу их ранжирования, а следовательно, и задачу их предварительной оценки;

3) выбор и ранжирование факторов меняется от исследования к исследованию и зависит от его объекта, предмета, целей и задач;

4) факторы взаимопереплетены, накладываются друг на друга, могут воздействовать не только на развитие региона, но и друг на друга, причем как усиливая, так и ослабляя либо друг друга, либо один или несколько факторов;

5) взаимопереплетение и взаимоналожение факторов усложняет оценку их влияния на развитие региона формирует необходимость системного и комплексного подхода в их исследовании, применении широкого арсенала методов анализа, как математического, так и экспертного.

Различные классификации факторов развития региона обусловлены необходимостью определения причин и условий, определяющих направления регионального развития, с одной стороны, и подходы к формированию государственной политики по отношению к региону, с другой.

Кроме того, выделение тех или иных ключевых групп факторов зависит и от целей и задач исследования. Поэтому разниться могут не только подходы к классификациям, но и методы анализа и оценки факторов развития региона. На взгляд автора, в методическом отношении процесс определения факторов неразрывно связан с методами их оценки. 


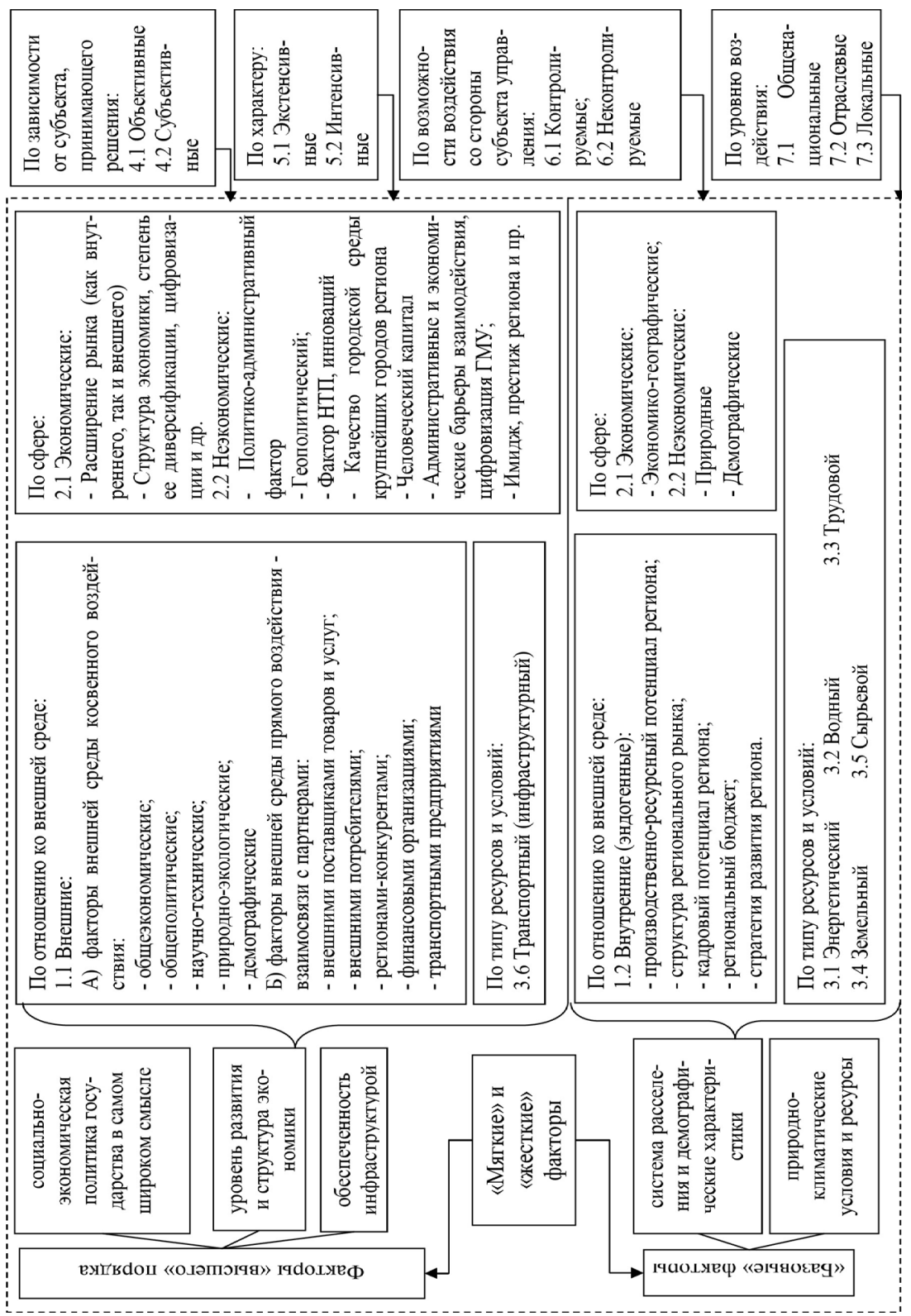

Рис. 1. Обобщающая схема факторов развития региона 
В литературе широко представлены подходы к анализу конкретных факторов (например, трудовых ресурсов [21, 22], капитала - как основных фондов региона [23], так и финансовых средств, элементов интеллектуального, человеческого капитала [24], предпринимательства [25] и пр.), имеются также исследования, направленные на комплексную оценку факторов развития региона в целом [26]. В большинстве своем предложенные оценки опираются на статистические методы, методы экономико-математического моделирования и позволяют, как определять роль отдельных факторов в развитии региона, так и служат основанием для последующей кластеризации регионов России, определения типичных особенностей развития выделенных групп регионов и формирования относительно унифицированных подходов к разработке государственной политики развития соответствующих групп регионов. Экономико-математические методы, обладая своими неоспоримыми достоинствами, в то же время имеют также и свои ограничения и должны дополняться методами экспертной оценки. Причем на разных этапах исследования на первый план выходят разные аналитические подходы. Предлагается следующая схема изучения факторов развития региона (см. рисунок 2).

Этапы, представленные на схеме, являются достаточно условными, так как на каждом из них осуществляется и подготовительная, и аналитическая работа, и работа по формулировке результатов. При выявлении недостаточности информации, ее дополнения, пересмотра на каждом их этапов возможно возвращение на предыдущие.

Наиболее важным, на взгляд автора, является подбор экспертов и предварительная оценка факторов развития региона поскольку от этого в наибольшей степени зависит конечный результат исследования. Важным моментом также является построение экономикоматематических моделей, обеспечение их достоверности.

Сформированные на основе проведенного анализа факторов выводы, являются чрезвычайно значимыми для последующих работ по определению приоритетов государственной политики развития региона, формированию и наполнению конкретных региональных программ и проектов, повышают управляемость всего процесса 
развития региона на основе достоверного знания о причинах, свойствах, зависимостях и закономерностях указанного процесса.

І этап - подготовительный

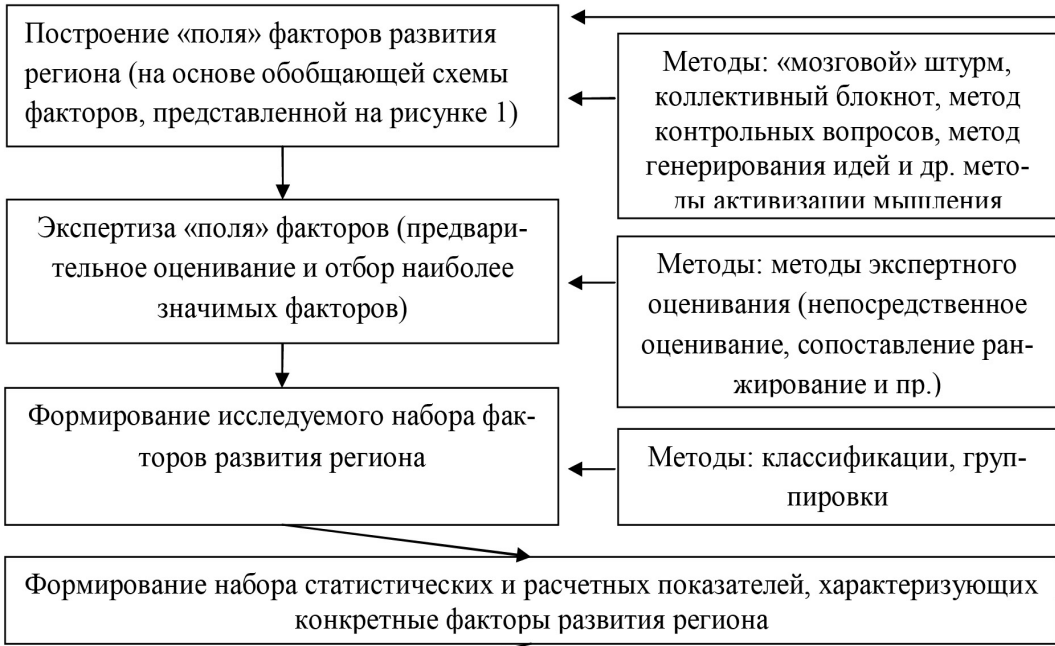

II этап - аналитический

Обработка (например, их сводка, группировка, приведение в сопоставимый вид) и анализ статистических показателей, взаимосвязей между ними; расчет средних и агрегированных показателей, их анализ

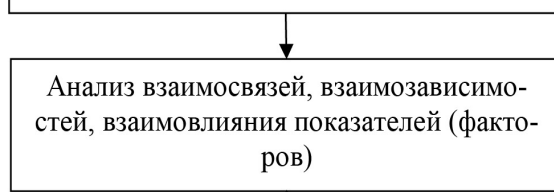

III этап - формулировк্

Подведение результатов анализа, формулировка выводов и обобщений, проблемных точек и потенциала развития региона

Методы: «сдвиг-доля», анализ динамики, средних величин, корреляционно-регрессионный анализ, факторный анализ, экономико-математическое моделирование и пр.

Методы: регрессионный анализ (расчет коэффициентов корреляции), факторный анализ, экономико-математическое моделирование и пр.

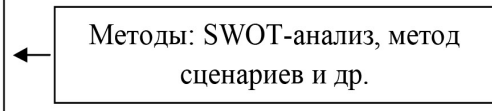

Определение ключевых направлений государственной политики развития региона

Рис. 2. Схема исследования факторов развития региона 
Таким образом, в настоящее время сложилось достаточно устойчивое определение понятия «фактор», под которым понимается совокупность причин, условий, существенных обстоятельств (предпосылок), движущих сил развития региона. В то же время работы, связанные с исследованием указанных факторов направлены либо на попытки их систематизации и классификации, либо на анализ конкретных факторов развития региона. На наш взгляд, эти процессы в методическом отношении являются неразрывными. Необходимо формирование теоретической базы, некоторого теоретического алгоритма описывающего весь процесс исследования факторов развития региона, от формирования «поля» факторов, до их предварительной оценки, ранжирования и глубокого анализа их взаимосвязи и степени влияния на развитие конкретного региона на базе широкого арсенала как экономико-математических, так и экспертных методов. Реализация указанного подхода позволит повысить качество аналитического сопровождения при принятии управленческих решений на уровне региона в целом и в рамках разработки региональных программ в частности.

\section{Список литературы}

1. Фактор // С.И. Ожегов. Толковый словарь русского языка. URL: https:// slovarozhegova.ru/word.php?wordid=33656 (дата обращения: 03.12.2020).

2. Фактор // Большая советская энциклопедия: [в 30 т.] / гл. ред. А. М. Прохоров. 3-е изд. М.: Советская энциклопедия, 1969-1978. URL: https://biblioclub.ru/index.php?page=dict\&dict_id=63 (дата обращения: 03.12.2020).

3. Гаврилов А.И. Региональная экономика и управление. М., 2002.

4. Минаев Ю.Н. Анализ факторов, влияющих на уровень социальноэкономического развития региона // Вестник ТГУ. выпуск 1 (69). 2008. C. 333-338.

5. Ускова Т.В. Управление устойчивым развитием региона: монография. Вологда: ИСЭРТ РАН, 2009. С. 141.

6. Власова Н.Ю. Структурная модернизация экономики крупнейших городов России. Екатеринбург: Изд-во Урал.гос.экон.ун-та, 2000. С. 148-163. 
7. Фетисов Г.Г., Орешин В.П. Региональная экономика и управление: Учебник. М.: ИНФРА-М, 2006. С. 29-31.

8. Шапкин И.Н. Управление региональным хозяйством: учебное пособие / И.Н. Шапкин, А.О. Блинов, Я.М. Кестер. М.: КНОРУС, 2005. C. $8-9$

9. Экономика, управление и финансы региона в период его экономического роста. Монография / С.В. Лаптев, С.А. Демкина, Л.И. Мещерякова и др. под общей ред. д-ра экон. наук, проф. С.В. Лаптева. Воронеж: ВГПУ, 2008. С. 15.

10. Сеньков В.И., Сенькова Н.В. Качество экономического роста регионов: теоретические аспекты, критерии оценки и методология анализа // Региональная экономика: теория и практики. 2010. № 32 (167). C. 12-18.

11. Коваленко Е. Региональная экономика и управление / Е. Коваленко, Г. Зинчук, С. Кочеткова, С. Маслова, Т. Полушкина, С. Рябова, О. Якимова. Учебное пособие. 2-е изд., перераб. и доп. СПб.: Питер, 2008. C. 126-127.

12.Грязнова М.А. Использование анализа «сдвиг-доля» в управлении развитием старопромышленного региона / М.А. Грязнова, 3.3. Муллагалеева // сб. ст. VI всерос. науч.-практ. конф. «Антикризисное управление: производственный и территориальный аспекты». Новокузнецк, 2009. С. 231-235.

13. Невейкина Н.В. Факторы развития региона // Ученые записки Орловского государственного университета. Серия: Гуманитарные и социальные науки. №1 (57), 2014. С. 78-85.

14. Кузнецова О.В. Типология факторов социально-экономического развития регионов России // Вестн. Моск. ун-та. сер. 5. география. 2014. № 2. C. 3-8.

15. Bailey D., Pitelis Ch., Tomlinson Ph.R. A place-based developmental regional industrial strategy for sustainable capture of co-created value // Cambridge Journal of Economics, 2018, no.42, pp. 1521-1542. doi:10.1093/cje/bey019

16. Goddard J., Robertson D., Vallance P. Universities, technology and innovation centres and regional development: the case of the North- 
East of England // Cambridge Journal of Economics, 2012, vol. 36, no. 3, pp. 609-627, https://doi.org/10.1093/cje/bes005

17. Karahasan B.C. Dynamics of regional new firm formation in Turkey // Review of urban \& regional development studies, 2015, vol. 27, no. 1, pp. 18-39. https://doi.org/10.1111/rurd.12031

18. Coffey W.J., Polèse M. The concept of local development: a stages model of endogenous regional growth // Regional Science, 1984, vol. 55, no. 1, pp. 1-12.

19. Dore P., Narayanan K. Inter-temporal differences in regional development // Area development and policy, 2020, vol. 5, no. 4, pp. 376-389. https:// doi.org/10.1080/23792949.2020.1741413

20.Liu G., Liu Y., Zhang Ch. Factor allocation, economic growth and unbalanced regional development in China // The world economy, 2018, vol. 41, no. 9, pp. 2439-2463. https://doi.org/10.1111/twec. 12572

21.Гармаев А.Б. Имитация динамики трудовых ресурсов Республики Бурятия / А.Б. Гармаев, А.Ю. Лосева // Вестник Бурятского государственного университета. Экономика и менеджмент. 2008. вып. 2. C. 20-27.

22. Шрамко И.В. Методические аспекты анализа эффективности использования трудовых ресурсов / И.В. Шрамко, Э.Б. Адельсеитова // International scientific review. 2019. №LIX. URL: https://cyberleninka. $\mathrm{ru} /$ article/n/metodicheskie-aspekty-analiza-effektivnosti-ispolzovaniyatrudovyh-resursov-1.

23. Кольцова Т.А., Агабекян С.Г. Экономико-статистическая Оценка основных фондов региона // Учет и статистика. 2018. №3 (51). URL: https:/cyberleninka.ru/article/n/ekonomiko-statisticheskaya-otsenkaosnovnyh-fondov-regiona (дата обращения: 03.12.2020).

24.Корицкий А.В. Велика ли отдача человеческого капитала в России? // ЭКО. 2018. №2 (524). URL: https://cyberleninka.ru/article/n/ velika-li-otdacha-chelovecheskogo-kapitala-v-rossii (дата обращения: 03.12.2020).

25. Барейко С.Н., Татарникова М.А. Развитие малого и среднего предпринимательства как фактор экономического роста Ленинградской области // Региональные проблемы преобразования экономики. 
2018. №11 (97). URL: https://cyberleninka.ru/article/n/razvitie-malogoi-srednego-predprinimatelstva-kak-faktor-ekonomicheskogo-rostaleningradskoy-oblasti (дата обращения: 03.12.2020).

26. Шогенов А.М. Диагностика и факторы социально-экономического развития регионов // Экономический анализ: теория и практика. 2005. № 2(35). C. 55-63.

\section{References}

1. Ozhegov S.I. Tolkovyy slovar' russkogo yazyka [S.I. Ozhegov. Explanatory dictionary of the Russian language]. https://slovarozhegova.ru/ word.php?wordid=33656 (accessed 03.12.2020)

2. Bol'shaya sovetskaya entsiklopediya [Great Soviet Encyclopedia] / ed. A.M. Prokhorov. M.: Sovetskaya entsiklopediya, 1969-1978. https:// biblioclub.ru/index.php?page $=$ dict\&dict_id=63 (accessed 03.12.2020)

3. Gavrilov A.I. Regional'naya ekonomika i upravlenie [Regional economics and management]. M., 2002.

4. Minaev Yu.N. Vestnik TGU. № 1 (69). 2008. P. 333-338.

5. Uskova T.V. Upravlenie ustoychivym razvitiem regiona [Management of sustainable development of the region]. Vologda: ISERT RAN, 2009. P. 141.

6. Vlasova N.Yu. Strukturnaya modernizatsiya ekonomiki krupneyshikh gorodov Rossii [Structural modernization of the economy of the largest cities in Russia]. Ekaterinburg: Izd-vo Ural.gos.ekon.un-ta, 2000. P. 148163.

7. Fetisov G.G., Oreshin V.P. Regional'naya ekonomika i upravlenie [Regional Economics and Management]. M.: INFRA-M, 2006. P. 29-31

8. Shapkin I.N., Blinov A.O., Kester Ya.M. Upravlenie regional'nym khozyaystvom [Regional economy management]. M.: KNORUS, 2005. P. 8-9.

9. Laptev S.V., Demkina S.A., Meshcheryakova L.I. et al. Ekonomika, upravlenie i finansy regiona $v$ period ego ekonomicheskogo rosta [Economy, management and finances of the region during the period of its economic growth]. Voronezh: VGPU, 2008. P. 15.

10. Sen'kov V.I., Sen'kova N.V. Regional'naya ekonomika: teoriya i praktiki. 2010. № 32 (167). P.12-18. 
11. Kovalenko E., Zinchuk G., Kochetkova S., Maslova S., Polushkina T., Ryabova S., Yakimova O. Regional'naya ekonomika i upravlenie [Regional economy and management]. SPb.: Piter, 2008. P.126-127.

12. Gryaznova M.A., Mullagaleeva Z.Z. sb. st. VI vseros. nauch.-prakt. konf. «Antikrizisnoe upravlenie: proizvod-stvennyy i territorial 'nyy aspekty» [Collection of articles VI All-Russian. scientific-practical conf. "Anti-crisis management: production and territorial aspects"]. Novokuznetsk, 2009. P. 231-235.

13. Neveykina N.V. Uchenye zapiski Orlovskogo gosudarstvennogo universiteta. Seriya: Gumanitarnye i sotsial'nye nauki. №1 (57), 2014. P. 78-85.

14. Kuznetsova O.V. Vestn. Mosk. un-ta. ser. 5. geografiya. 2014. № 2. P. 3-8.

15. Bailey D., Pitelis Ch., Tomlinson Ph.R. A place-based developmental re-gional industrial strategy for sustainable capture of co-created value. Cambridge Journal of Economics, 2018, no.42, pp. 1521-1542. doi:10.1093/cje/bey019

16. Goddard J., Robertson D., Vallance P. Universities, technology and innovation centres and regional development: the case of the North-East of England. Cambridge Journal of Economics, 2012, vol. 36, no. 3, pp. 609-627, https://doi.org/10.1093/cje/bes005

17. Karahasan B.C. Dynamics of regional new firm formation in Turkey. Review of urban \& regional development studies, 2015, vol. 27, no. 1, pp. 18-39. https://doi.org/10.1111/rurd.12031

18. Coffey W.J., Polèse M. The concept of local development: a stages model of endogenous regional growth. Regional Science, 1984, vol. 55, no. 1, pp. 1-12.

19. Dore P., Narayanan K. Inter-temporal differences in regional development. Area development and policy, 2020, vol. 5, no. 4, pp. 376-389. https://doi.org/10.1080/23792949.2020.1741413

20. Liu G., Liu Y., Zhang Ch. Factor allocation, economic growth and unbal-anced regional development in China. The world economy, 2018, vol. 41, no. 9, pp. 2439-2463. https://doi.org/10.1111/twec. 12572

21. Garmaev A.B., Loseva A.Yu. Vestnik Buryatskogo gosudarstvennogo universiteta. Ekonomika i menedzhment. 2008. № 2. P. 20-27.

22. Shramko I.V., Adel'seitova E.B. International scientific review. 2019. №LIX. https://cyberleninka.ru/article/n/metodicheskie-aspek- 
ty-analiza-effektivnosti-ispolzovaniya-trudovyh-resursov-1 (accessed 03.12.2020).

23. Kol’tsova T.A., Agabekyan S.G. Uchet $i$ statistika. 2018. №3 (51). https://cyberleninka.ru/article/n/ekonomiko-statisticheskaya-otsenka-osnovnyh-fondov-regiona (accessed 03.12.2020).

24.Koritskiy A.V. EKO. 2018. №2 (524). https://cyberleninka.ru/article/n/velika-li-otdacha-chelovecheskogo-kapitala-v-rossii (accessed 03.12.2020).

25. Bareyko S.N., Tatarnikova M.A. Regional'nye problemy preobrazovaniya ekonomiki. 2018. №11 (97). https://cyberleninka.ru/article/n/ razvitie-malogo-i-srednego-predprinimatelstva-kak-faktor-ekonomicheskogo-rosta-leningradskoy-oblasti (accessed 03.12.2020).

26. Shogenov A.M. Ekonomicheskiy analiz: teoriya i praktika. 2005. № 2(35). P. 55-63.

\section{ДАННЫЕ ОБ АВТОРЕ}

Москвитина Мария Александровна, доцент кафедры государственного и муниципального управления, канд.экон.наук Сибирский институт управления - филиал Российской академии народного хозяйства и государственной службы ул. Нижегородская, 6, г. Новосибирск, 630102, Российская Федераичи moskvitina-ma@ranepa.ru

\section{DATA ABOUT THE AUTHORS}

Moskvitina Maria Alexandrovna, Associate Professor of the Department of State and Municipal Administration, Candidate of Economic Sciences

Siberian Institute of Management-Branch of the Russian Academy of National Economy and Public Administration 6, Nizhegorodskaya Str., Novosibirsk, 630102, Russian Federation moskvitina-ma@ranepa.ru

SPIN-code: 1459-8436

ORCID: 0000-0002-6474-1946 